\title{
Water Stability of Metal-Organic Framework HKUST-1
}

\author{
Angela Terracina ${ }^{a, b}$ and Gianpiero Buscarino ${ }^{\star, b}$ \\ ${ }^{a}$ Dipartimento di Fisica e Chimica, Università di Palermo, Palermo 90123, Italy \\ ${ }^{b}$ Dipartimento di Fisica e Astronomia, Università di Catania, Catania 95123, Italy
}

Email: gianpiero.buscarino@unipa.it (G. B.)

\begin{abstract}
Metal-organic frameworks (MOFs) are a new class of crystalline porous materials, having wide pores which provide extremely high specific surface areas, larger than those typically observed in more common porous materials like zeolites or activated carbons. This peculiar property combined with the frequent presence of open-metal sites, makes them very promising for a broad range of applications, spacing from gas storage or separation, drug delivery, toxic air removal, chemical detectors, etc. However, the industrialization of MOFs is still facing difficulties because of their low stability to water or even air moisture, a substance difficult to avoid in applications like those mentioned. Another issue concerning MOF industrialization consists in the low bulk density of the micrometric powder grains, which typically constitute such materials. Unfortunately, their low mechanical stability seems to make difficult even to enhance the packaging by simple mechanical compaction. In this review, we will particularly focus on the current state of art involving the MOF HKUST-1, especially on the degradation process involved when this MOF interacts with water molecules. Furthermore, we will show the connection between water and mechanical stability, bringing to attention of a study where solid tablets of HKUST-1 powder have been realized without any loss of crystallinity or porosity because of an accurate study on the effects of different degree of hydration during the tableting phases. In addition, in order to highlight the causes of damages induced in the framework upon interaction with water, a comparison with other two copper carboxylate MOFs will be shown, namely STAM-1 and STAM-17-OEt, which differ from HKUST-1 uniquely for the organic ligands.
\end{abstract}

Keywords water stability, HKUST-1, mechanical compaction, MOF hydrolysis pattern, degradation process

\section{Introduction}

Metal-organic frameworks (MOFs) are a promising class of porous crystalline materials with great potentialities in a wide range of industrial applications. Composed of combinations of metallic knots and organic linkers, more than 70,000 different structures are currently recognized as MOFs. ${ }^{[1-5]}$ Their specific surface area typically exceeds $1,000 \mathrm{~m}^{2} / \mathrm{g}$, reaching sometimes even $10,000 \mathrm{~m}^{2} / \mathrm{g} .{ }^{[2]}$ Such a remarkable porosity is due to the possibility to combine up to $50 \AA$ long extended organic molecules via different possible configurations, arising from the coordination geometry of the metallic junctions and it opens the doors for applications in gas storage $\left(\mathrm{H}_{2}, \mathrm{CH}_{4}, \cdots\right)$ and then in the field of renewable energies. ${ }^{[1-3,6]}$ If the metallic junction is composed of a polynuclear cluster arising from a chelation of two or more metal ions, it is called secondary building unit $(S B U) .^{[1-3,5]}$ The metal sites may also have a particular affinity with some gaseous substances, thus allowing to selectively adsorb pollutants like $\mathrm{CO}_{2}, \mathrm{NH}_{3}$, cyclohexane and many others, leading to potential applications in the removal of toxic industrial chemicals. ${ }^{[2,3,7-12]}$ However, only very few applications have been already introduced in commercial use, ${ }^{[13,14]}$ mainly because of two big challenges: the extremely sensitivity to water (even to air moisture ${ }^{[8,15]}$ and the typical poor packaging of MOFs, generally synthesized in the form of powders with low bulk density. ${ }^{[16,17]}$ Both the issues have been constantly investigated by researchers, but several significant aspects are still unclear. Examples of these are the deep knowledge of the hydrolysis/dissociation mechanisms induced by the interaction with water molecules or even finding cheap methods, which might allow to produce water-resistant or well-packaged MOFs without loss in porosity, crystallinity, or performance..$^{[4,8,15,16]}$ In this review, both these topics are covered, specially focusing on the water stability of the MOF HKUST-1, after a brief overview based on MOFs in general. Even other two MOFs will be treated, STAM-1 and STAM-17-OEt, composed of the same SBU commonly called paddlewhee/ but different organic linkers which lead to markedly diverse properties.

Since its first appearing in a scientific journal in 1999, HKUST-1 or Cu-BTC, has been one of the most investigated MOFs. ${ }^{[18,19]}$ In fact, it is widely used as model for MOF research because of the ease of getting a high quality industrial-scale HKUST-1 material and for its peculiar properties as selective adsorbent. ${ }^{[11,12]}$ The other two MOFs shown in this review, STAM-1 and STAM-17-OEt, are much more recent but very promising, especially in the research field. ${ }^{[20,21]}$ In fact, despite the similarities with HKUST-1, they have a high water stability and a flexible crystalline structure, which means that the crystal undergoes spontaneous lattice transitions when subjected to determined external stimuli. ${ }^{[20-23]} \mathrm{A}$ deeper understanding of this aspect can contribute to giving a significant boost to the search of stable MOF structures.

\section{Water Stability in Metal-Organic Frameworks}

"Water is everywhere!" is the overture of the review about the water adsorption in MOFs written by Canivet and co-authors. ${ }^{[15]}$ In fact, even though MOFs have great potentialities for methane or hydrogen storage and for the capture of carbon dioxide from flue gases, ${ }^{[1,3,4,7,11,12,15,24]}$ outside of the laboratories natural or industrial gas steams or even the simple air have generally significant percentages of water 
vapor/humidity, and therefore the MOF behavior in the presence of water is a critical aspect to investigate. ${ }^{[8]}$ Even worse, for example, water vapor is actually one of the main components in industrial flue gas, then it cannot be ignored when studying performances in the capture of gases like $\mathrm{CO}_{2}$. Unfortunately, even the first discovered MOFs, MOF-5 and HKUST-1, turned out to be strongly water-sensitive with critical consequent effects, and also afterwards it has been remarked that, generally, MOF performances in humid environments are typically not enough to fit the industrial requirements. ${ }^{[4,8,15]} \mathrm{A}$ possible dehydration step of bio-fuel streams is downright unthinkable, because it would require an energy exceeding that released by the combustion process itself. ${ }^{[8]}$ However, it is also true that, for determined applications, certain soluble MOFs called Bio-MOFs are interesting for in vivo medical applications, for example, as drug carriers. ${ }^{[7,10,15]}$ Introducing a definition as general as possible, a water stable MOF should have the property that, after handling it in laboratory air and/or exposing it to a reasonable amount of air moisture, the porous structure is retained. ${ }^{[8]}$ In addition, from an industrial point of view, it might also be crucially important that the water-stable material could return to its original form at the end of each cycle of adsorption/gas separation or purification: in this cases, a reversible hydration process would be required. ${ }^{[8]}$

\section{Structural factors linked to water stability}

Since the beginning of the first MOF synthesis, the strength of the metal-ligand bond has constituted a problem. The first MOFs, indeed, frequently lacked of architectural stability and then typically collapsed upon removal of solvents or exchange of ions in the pores, and then of a total absence of chemical stability because of such relatively weak bonds. ${ }^{[1]}$ After the introduction of charged chelating linkers (whom the first one was actually the BTC linker), the metal-ligand bond has been increased and, additionally, such change of the linkers could balance that of the metal centers and avoid ion accumulation and even the interpenetration. Because of the combination of such linkers with SBUs, the removal of the solvent did not lead to the collapse of the structure for many new MOFs. ${ }^{[1]}$ However, such bonds are frequently strong enough to avoid water decomposition.

After several efforts and compared studies, some structural factors governing the stability of MOFs in presence of water have been individuated. ${ }^{[8]}$ Generally, MOF water resistance may depend on both the electronic and the steric effects of the ligand on the metal node. ${ }^{[8,15]}$ In fact, the main structural property that makes a MOF water stable is the inertness of the metal cluster: in this case, the degradation mechanism is not favored. ${ }^{[8,15]}$ Another point of view for the study of the (in)stability of a MOF is to evaluate the strength of metal-ligand coordination bond, because it typically represents the weak point of the structure ${ }^{[8]}$ Even if a specific MOF has not an inert metal, there are cases in which we can talk of kinetic stability: this latter property is governed by the activation energy barrier, which depends on the specific pathway of the potential dissociation reaction. ${ }^{[8]}$ Two examples of kinetic factors, which can play an important role in the increase in hydrolysis activation energy, are hydrophobicity and ligand sterics. ${ }^{[8]}$ The reasoning at the basis is that a dissociation mechanism takes place only if the oxygen of a water molecule can sufficiently approach the metal to allow the establishment of an interaction between the electron orbitals. ${ }^{[8,15]}$ In addition, it is also necessary that the energy associated to such interaction is large enough to exceed the activation energy barrier of the reaction. ${ }^{[8,15]}$ It is expected that MOFs having this characteristic could decompose when submerged in liquid water but they would be stable after exposure to high humidity conditions. ${ }^{[8]}$
Despite this, there are few notable exceptions which does not have inert metals, but are thermodynamically stable: probably in some cases so strong kinetic factors are involved that they make the barrier of the irreversible degradation fatally high. ${ }^{[8,25,26]}$

Two main degradation mechanisms acting in MOFs exposed to water have been outlined:

(1) The ligand displacement reaction, which involves the inclusion of a water molecule into the metal-ligand bond;

(2) The hydrolysis reaction, which implicates the breakage of the metal-ligand bond and the dissociation of the water molecule. ${ }^{[15,27]}$

The more diffused dissociation mechanism in MOF field is the latter and, as shown in the following section, it is also the reaction that occurs in HKUST-1.

Pore hydrophobicity is another property that can avoid water adsorption into the pores of a MOF or it can simply prevent the formation of water clusters around the metal centers. ${ }^{[8]}$ In fact, water clustering within MOF pores seems to have a significant contribution in promoting degradation reactions. ${ }^{[8,28,29]}$ For example, some works have reported on degradation mechanism phenomena in IRMOFs, showing that the breakage of the metal-oxygen bonds had happened only upon the formation of water clusters next to the metal centers. ${ }^{[28,29]}$

As it is probably clear at this point, a deep understanding about the breakdown mechanism of MOFs interacting with water is a crucial step for their development in commercial or industrial applications and technologies. ${ }^{[4,8,15]}$ In the following section, the state of the art about the stability of HKUST-1 will be deepened, explaining HKUST-1 decomposition process in great detail.

\section{HKUST-1}

HKUST-1 (Hong Kong University Science and Technology) or $\mathrm{Cu}_{3}(\mathrm{BTC})_{2}$ was synthesized in 1999 by Chui and coworkers, and it is formed by copper paddlewheels and tritopic benzene-1,3,5-tricarboxylate (BTC) linkers. ${ }^{[18]}$ It has a face-centered-cubic crystal lattice, with three distinct internal pores, displaying openings of about 9,11 and $14 \AA$, respectively. ${ }^{[18,19,30]}$ By standard synthesis protocols, HKUST-1 crystallizes with a water molecule coordinated to each $\mathrm{Cu}^{2+}$ ion. ${ }^{[1,19,31]}$ The dehydrated structure is typically obtained by a simple heating process at temperature ranging from 370 to $420 \mathrm{~K}$ under low pressure. ${ }^{[18,19,31]}$ The desorption of the water molecules from the copper ions leads to the changing of the color of the MOF from turquoise to dark-blue. ${ }^{[18,31,32]}$ Its bulk density is about $\sim 0.4 \mathrm{~g} / \mathrm{cm}^{3}$, whereas its calculated crystalline density (for a dehydrated HKUST-1) is $\sim 0.88 \mathrm{~g} / \mathrm{cm}^{3}$. ${ }^{[3,34]}$

It is well-known that massive hydration conditions or water cycles seriously compromise the structure and the performances of HKUST-1. ${ }^{[8,15,21,35-45]}$ However, only few works face the water degradation issue at atomic scale level.

Among the various points of view and different hydrolysis models, the main cornerstone is that HKUST-1 is a very hydrophilic MOF: In fact, it is well-known that polar molecules like water have a large affinity for the $\mathrm{Cu}^{2+}$ of the paddlewheel and such copper ions are defined open-metal sites for the MOF. ${ }^{[8,15,31,39-41,46-49]}$ In contrast to some other MOFs which may show the coordination sites blocked by ligands, in HKUST-1 the metal sites are on the walls of the pores, making the $\mathrm{Cu}$ sites completely accessible. ${ }^{[50]}$ For this reason, the dehydration process for this kind of MOFs is also frequently named activation, because it makes the open metal sites active. If the color of the dehydrated MOF is dark violet/blue navy, it only takes few minutes of exposure to air moisture to drastically change it 
again into light turquoise. . $^{[31,35,41,51-52]}$

However, in general, the copper ions are not the only possible HKUST-1 adsorption sites for small molecules. In this regard, several systematic searches of all of the potential and preferential adsorption sites have been deeply carried out via molecular simulations. ${ }^{[38,47,53-55]}$

In Figure 1, the main potential adsorption sites of HKUST-1 are represented with the spheres marked by the numbers I, I', II and III. It has been observed that a water molecule preferentially adsorbs close to $\mathrm{Cu}^{2+}$ and then in sites I and I', whereas apolar molecules like methane adsorb preferably at the site III. ${ }^{[47]}$

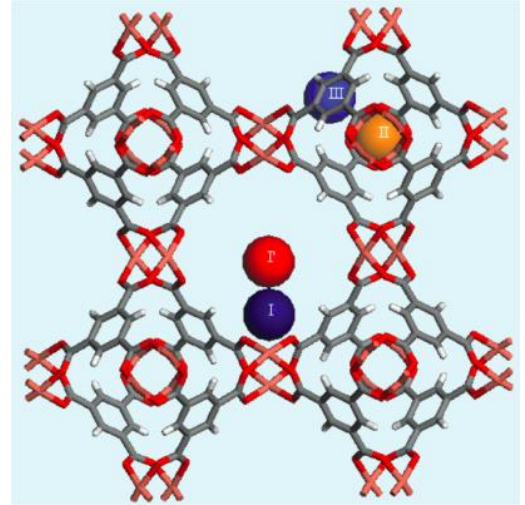

Figure 1 Representation of possible sorption sites I, I', II, and III in the structure of HKUST-1 viewed along the [100] direction. Copper atoms in pink, oxygens in red, carbons in grey, hydrogens in white. Reprinted with permission from J. Am. Chem. Soc. 2012, 134, 1486-1489. Copyright 2012 American Chemical Society. ${ }^{[38]}$

More in detail, site I corresponds to that occupied by the water molecules directly coordinated with $\mathrm{Cu}$, whereas in site I' there can be found water molecules bonded through hydrogen bonds to water molecules directly adsorbed at site . $^{[38,47]}$

Gul-E-Noor and co-authors ${ }^{[46]}$ confirmed and deepened this result experimentally by a ${ }^{1} \mathrm{H}$ MAS NMR study. They studied the water-MOF interaction for HKUST-1 during a continuous hydration under air moisture for $80 \mathrm{~h}$. Their interpretation of the data is based on the idea of a hydration process which can be divided in 2 main steps:

(1) During the first phase of air exposure, they have observed the progressive adsorption of water on the unoccupied metal sites (i.e., sites I), detecting a co-existence of paddlewheels with either one or two water molecules per $\mathrm{Cu}$ pair (namely species $\mathrm{H}_{2} \mathrm{O}-\mathrm{I}$ and $\mathrm{H}_{2} \mathrm{O}-\mathrm{Il}$, respectively). With the increasing of the exposure time up to $20 \mathrm{~h}$, the number of paddlewheels with two water molecules has grown. The authors have estimated an instant value of $1.2 \mathrm{H}_{2} \mathrm{O} / \mathrm{Cu}$ at exposure time of $9 \mathrm{~h} 30 \mathrm{~min} .{ }^{[46]}$

(2) After $20 \mathrm{~h}$, they have observed the appearing and then the increasing of a new signal, which have arisen from paddlewheels with more than two water molecules per $\mathrm{Cu}$ pair (namely species $\mathrm{H}_{2} \mathrm{O}-I I I$ ), due to the addition of a second water molecule per $\mathrm{Cu}$ site (which corresponds to the occupation of site l' of Figure 1). Furthermore, from the $56^{\text {th }}$ to the $80^{\text {th }}$ hour, only this signal is detected on the NMR spectra with no further changes in intensity. ${ }^{[46]}$

It is noteworthy that the resonance lines of the species $\mathrm{H}_{2} \mathrm{O}-\mathrm{I}$ have a higher chemical shift than $\mathrm{H}_{2} \mathrm{O}-\mathrm{II}$ : the authors claim that it is a consequence of different coupling of the two unpaired electrons when one or both the metal centers are bonded to water. ${ }^{[46]}$ In fact, along with the different distribution of spin density, even the coordination environment of the cop- per ions change, switching between square planar to square pyramidal, and therefore when there is one $\mathrm{H}_{2} \mathrm{O} / \mathrm{Cu}$ pair, the two $\mathrm{Cu}^{2+}$ have different environment and coordination mode. ${ }^{[46]}$ Grajciar and co-authors ${ }^{[53]}$ have also confirmed that the free paddlewheel and that with one $\mathrm{Cu}^{2+}$ center occupied are not equivalent, since the second adsorption result is slightly weaker than the first one.

Similar information can be extracted studying the HKUST-1 water isotherm at $298 \mathrm{~K}$ shown in Figure $2 .{ }^{[39,56]}$

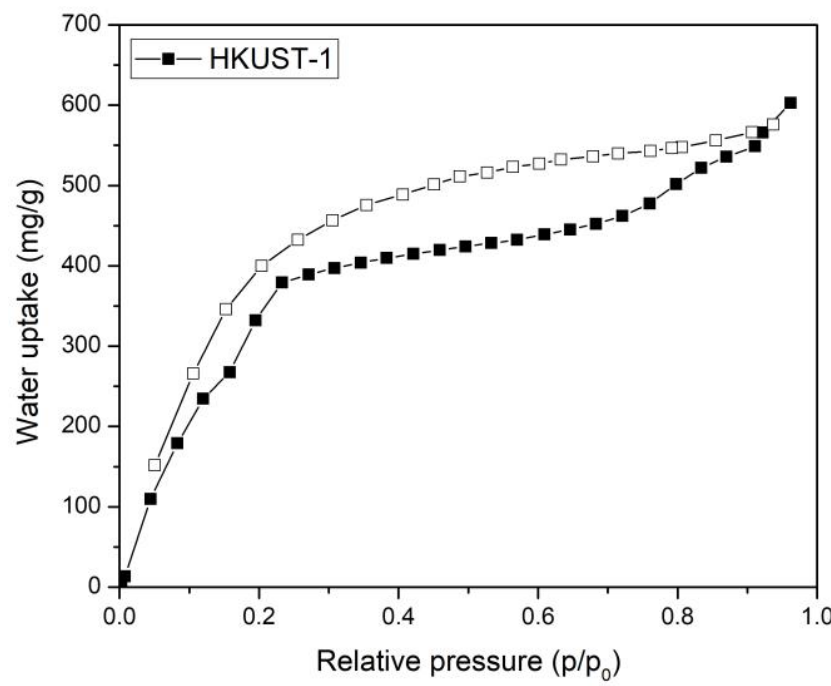

Figure 2 Water adsorption/desorption isotherms of HKUST- 1 measured at $25^{\circ} \mathrm{C}$. Adsorption - full points, desorption - empty points. Reprinted and adapted with permission from J. Phys. Chem. C 2018, 123, 1730-1741. Copyright 2018 American Chemical Society. ${ }^{[56]}$

In the lower pressure range $\left(p / p^{0}=0.1-0.3\right)$, the curve consists of a two-step trend, indicating two distinguishable processes. Presumably, the first one indicates water coordination to the copper sites and, subsequently, the second process represents either the filling of the rest of the large hydrophilic pores or the filling of the smaller ones, which have no metal site and then have a hydrophobic character, enhanced by the BTC linkers. ${ }^{[39]}$ Concerning higher relative pressures, at about $p / p^{0}=$ 0.4 there is a saturation region and after $p / p^{0}=0.9$ another slight increases, probably due to the water condensation inside the pores. ${ }^{[39]}$ The small hysteresis of the desorption branch can be attributed to the strong hydrogen bonds established among the water molecules adsorbed. ${ }^{[39]}$ A residual of not-desorbed water was observed in the lower pressure range: the cause is probably the chemisorption-favorable nature of the bonds established by the water molecules on the copper sites, meaning that high temperatures are always necessary to fully desorb such molecules and then activate the metal sites. ${ }^{[8,39]}$

\section{Models Concerning HKUST-1 Water Degradation}

Many works have drowned the possible decomposition processes, which might take place in HKUST-1 framework. The scope of this section is to offer an overview of the main common cornerstones of such models, although it is quite difficult to summarize them in a single all-inclusive picture, since each work is based on experimental setups which had involved different environments with different relative humidity, different exposure time, hydration conditions and temperatures as well as consequent effects studied from completely different points of view. For example, although all of these works generally show PXRD patterns with drastic reduction in the intensity of the peaks or a dramatic decrease of the BET area values after 
a certain degree of hydration, it is hard to definitively establish after which hydration level the first traces of hydrolysis occur within the lattice and, even more important, the details on what happens at atomic scale level. ${ }^{[8,15,21,35,38,41]}$ Despite this, with some precautions, it is possible to define a general description of the water degradation process. For example, a common conclusion is that the decomposition mechanism starts with the breakage of one or more $\mathrm{Cu}-\mathrm{O}$ bonds of the paddlewheels. $^{[8,15,21,35-37,42,53-55,61,62]}$ Ab initio molecular dynamics (AIMD) simulations have shown that the introduction of water molecules in the framework leads to a "violent oscillation" of the $\mathrm{Cu}-\mathrm{O}$ bond length, whereas the first occupation of a metal site causes a distancing between the copper and its adjacent bonded oxygens. ${ }^{[55]}$ In the view of Xue and co-authors, ${ }^{[55]}$ the paddlewheel unit with the elongated $\mathrm{Cu}-\mathrm{O}$ bond lengths may be considered as a precursor state for the MOF hydrolytic breakdown. ${ }^{[55]}$ However, it has been estimated that high water concentrations occur for the trigger of the hydrolysis. ${ }^{[5]}$ Another common result reached in many other works is the identification of the water condensation (or clustering) phenomenon inside the pores as a necessary condition for the begin of the hydrolysis in HKUST-1. ${ }^{[8,15,27,38,41,42,51,57]}$ As already mentioned in the previous section, this idea has been widely applied to MOFs. In particular, the presence of condensed water as the hydrolysis begins was experimentally determined by Tan and co-authors, ${ }^{[42]}$ via pressure and temperature dependence studies. They have also observed that the HKUST-1 structure had remained intact when the experimental conditions did not favor the water condensation. Accordingly, Giovine and co-authors ${ }^{[57]}$ showed that HKUST-1 samples exposed to water vapor significantly above the boiling temperature (about $420 \mathrm{~K}$ ) were surprisingly stable whereas, in contrast, they were readily hydrolyzed at lower temperatures like $350-370 \mathrm{~K}$, at which water can condense.

\section{Details about the HKUST-1 degradation process}

Depending on the water content inside HKUST-1 network, different decomposition products may be observed. ${ }^{[35,43,57,58]}$ One of the most significant identifications of such products has been done by Todaro and co-authors, by the use of EPR spectroscopy. ${ }^{[35]}$ In the following the structural processes taking in HKUST-1 upon interaction with air moisture for a long time will be explained in detail.

The hydrolysis effects have been extrapolated by analyzing the changes registered in the EPR spectra acquired at both 77 and $300 \mathrm{~K}$, which are reported in Figures 3 and 4, respectively. ${ }^{[35]}$
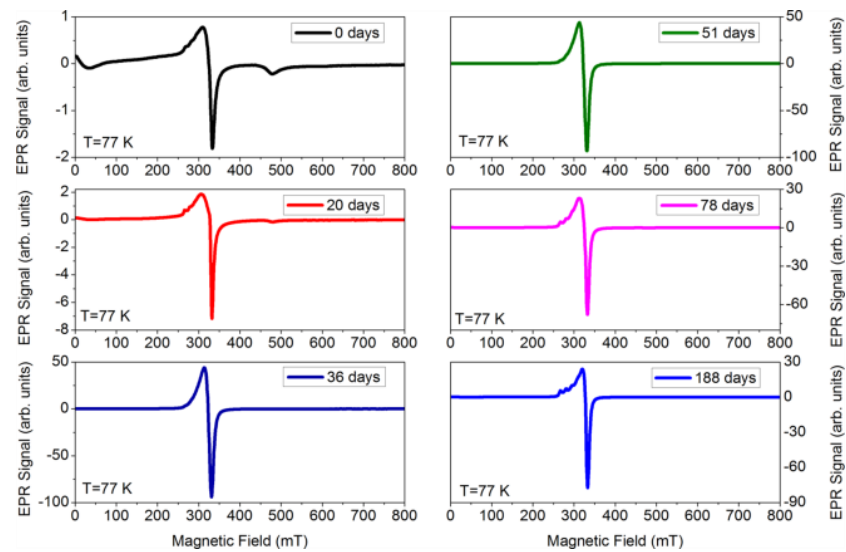

Figure 3 EPR spectra obtained at $77 \mathrm{~K}$ for a sample of HKUST-1 powder at different times of exposure to air moisture. Reprinted with permission from J. Phys. Chem. C 2016, 120, 12879-12889. Copyright 2016 American Chemical Society. ${ }^{[35]}$
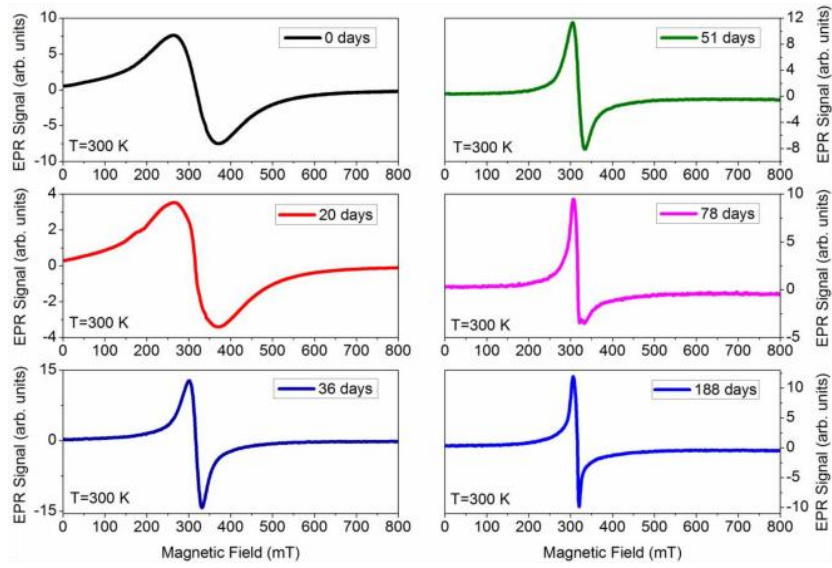

Figure 4 EPR spectra obtained at $300 \mathrm{~K}$ for a sample of HKUST-1 powder at different times of exposure to air moisture. Reprinted with permission from J. Phys. Chem. C 2016, 120, 12879-12889. Copyright 2016 American Chemical Society. ${ }^{[35]}$

Furthermore, enabling the hydration of the HKUST-1 sample exclusively through the small opening of the long and narrow EPR glass tube (about $0.3 \mathrm{~cm}$ diameter and about $16 \mathrm{~cm}$ in length), they have been able to slow down the hydration so that they could identify and analyze each step of the process in great detail. ${ }^{[35]}$ Combining their results with other similar studies, the main stages of the decomposition pathway identified until now are resumed in the following paragraphs. ${ }^{[35,37,43,44,55]}$

First stage: the water adsorption on the $\mathrm{Cu}$ sites. As above mentioned, the preferential adsorption site in HKUST-1 is on the copper, and then the first stage is the simple adsorption of the water molecule on the $\mathrm{Cu}^{2+}$ ions. In fact, upon adsorption, the oxygen of the adsorbed $\mathrm{H}_{2} \mathrm{O}$ shares a free electron pair with the $\mathrm{Cu}^{2+}$ ion, establishing an out-of-plane bond. ${ }^{[8,55]}$ This would lead to an elongation of the $\mathrm{Cu}-\mathrm{O}$ bonds. ${ }^{[55]}$ Xue and co-authors ${ }^{[55]}$ observed by DFT calculations that the first adsorbed water molecule might already tilt down and break the $\mathrm{Cu}-\mathrm{O}$ bond, leading to a ligand displacement (Figures 5 and 6), but water dissociation is both thermodinamically and kinetically unlikely at this stage, and therefore hydrolysis is not yet favored at this low water loading. ${ }^{[55]}$ The elongation of the $\mathrm{Cu}-\mathrm{O}$ bonds also causes an expansion of the dimensions of the unit cell of the framework, detectable by PXRD. ${ }^{[35]}$

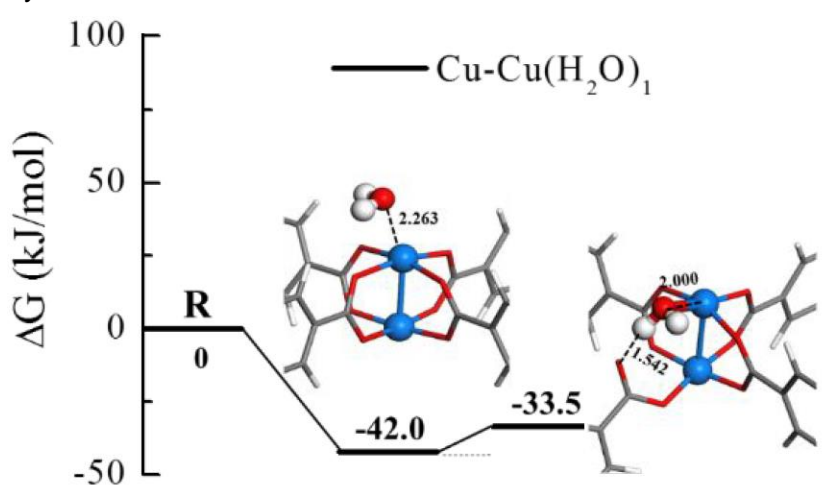

Figure 5 A selection of the calculated possible steps of the paddlewheel in presence of one water molecules per $\mathrm{Cu}$ pair during the hydrolytic process. Reprinted and adapted with permission from J. Phys. Chem. C 2019, 124, 1991-2001 Copyright 2019 American Chemical Society. ${ }^{[55]}$ 


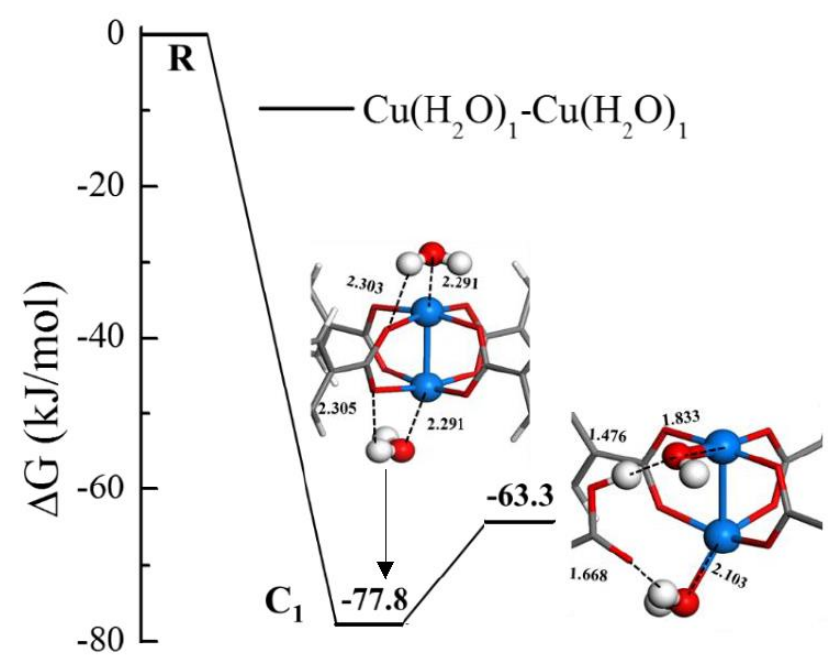

Figure 6 A selection of the calculated possible steps of the paddlewheel in presence of two water molecules per $\mathrm{Cu}$ pair during the hydrolytic process. Reprinted and adapted with permission from J. Phys. Chem. C 2019, 124, 1991-2001 Copyright 2019 American Chemical Society. ${ }^{[5]}$

Todaro and co-authors observed during the first 20 days of exposure to air moisture only reversible changes to the EPR spectra of their samples. As already mentioned, the paramagnetic centers present in an activated HKUST-1 sample are the solely $E^{\prime \prime}(\mathrm{Cu})$ triplet centers (namely the $S=1$ spin centers of the coupled paddlewheel of the activated HKUST-1) and $\left[\mathrm{Cu}\left(\mathrm{H}_{2} \mathrm{O}\right)_{6}\right]^{2+}$ centers, which are synthesis defects also presents in the pristine material. ${ }^{[63]}$

The main effect observed during this period of 20 days is a strong reduction in intensity (about 65\%) of the EPR signal obtained at room temperature: a possible interpretation given by the authors was a drastic reduction of the concentration of $\mathrm{E} "(\mathrm{Cu})$ centers: ${ }^{[35]}$ such effect would be due to the formation of a $\sigma$ bond between the $\mathrm{Cu}^{2+}$ ions within the paddlewheel. ${ }^{[35]}$ The formation of this bond would not damage irreversibly the network, but it would make the paddlewheels involved EPR silent. ${ }^{[35]}$ Also, the BET area values obtained by nitrogen isotherms did not show any reduction, supporting the hypothesis of a preserved framework. Accordingly, upon a simple activation process, the authors have obtained a complete recover of the EPR signal. ${ }^{[35]}$ In Figure 7, the stage just described is represented by the transition from (a) to (b). However, subsequent measurements carried out by EXAFS fits showed that there is a distancing of the two $\mathrm{Cu}^{2+}$ ions, making the establishment of an $\sigma$ bond between them hardly probable. For this reason, the question has remained opened but, anyway, it is certain that the first stage consists of in a softly hydrated material affected by a fully reversible change.

Second stage: the beginning of hydrolysis. From the $20^{\text {th }}$ to the $50^{\text {th }}$ day of hydration, Todaro and co-authors ${ }^{[35]}$ observed drastic changes in the EPR spectra of their samples. Those obtained at room temperature showed a narrowing of the resonance, whereas those acquired at $77 \mathrm{~K}$ exhibited an intense resonance centered at about $320 \mathrm{mT}$, similarly to the peak ascribed to the $\mathrm{S}=1 / 2$ spin centers of the $\left[\mathrm{Cu}\left(\mathrm{H}_{2} \mathrm{O}\right)_{6}\right]^{2+}$ but with a lineshape well distinguishable from that. ${ }^{[35]}$ Similar changes in the EPR signal have been also found elsewhere. ${ }^{[44]}$ According to their interpretation, such changes are due to the appearing of a new paramagnetic center within the material, which has been named $E^{\prime} 1(\mathrm{Cu})^{\left[{ }^{[35]}\right.}$ This new EPR signal would arise from the progressive formation of $\mathrm{Cu}^{2+} / \mathrm{Cu}^{1+}$ paddlewheels, which contribute to the EPR signal as $S=1 / 2$ spin centers.
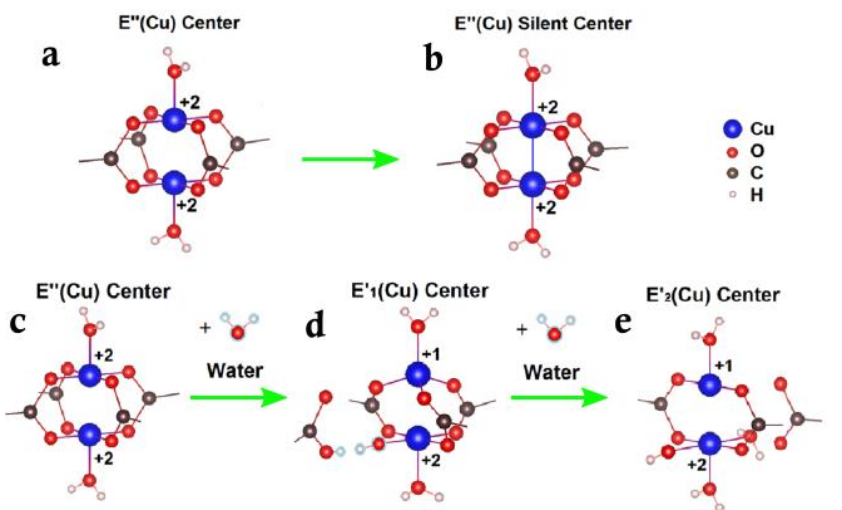

Figure 7 Schematic representation of the evolution of the copper paddlewheel in HKUST-1 upon exposure to air moisture. The different magnetic centers are labelled: $(a, c) E "(C u),(b)$ silent E"(Cu), (d) E'1(Cu), (e) E'2(Cu). Reprinted and adapted with permission from J. Phys. Chem. C 2016, 120(23), pp.12879-12889. Copyright 2016 American Chemical Society. ${ }^{[35]}$

More in detail, the oxidation state of one of the copper of the paddlewheels (the non-silent ones) changes from $2+$ to $1+$, but the resulting $\mathrm{Cu}^{+}$ion is EPR silent: therefore, the EPR signal of $\left.\mathrm{E}^{\prime} 1 \mathrm{Cu}\right)$ centers arise only from one $\mathrm{Cu}^{2+}$ of the pair in such new paddlewheel structures (Figure 7d). ${ }^{[35]}$ The hydrolysis of the $\mathrm{Cu}-\mathrm{O}$ bonds, leading to the partial detaching of a carboxylate bridge and the reduction of the coordination number from 5 to 4 , allows the change in both the oxidation state and in the geometry, which becomes tetrahedral. ${ }^{[35]}$ The adsorbed water substituting the ligand is dissociated and it has transferred one of the two hydrogens to the oxygen of the carboxylate bridge, after overcoming a very low barrier. ${ }^{[55]}$ However, this configuration is only metastable because it suffers to a relevant local strain, and then it quickly relaxes to another structure. The presence of strain is also suggested by the absence of the hyperfine structure on the peak centered at $\sim 320 \mathrm{mT}{ }^{[35]}$ This stage of the process is already irreversible: it has been demonstrated that, once at this phase, the attempt of an activation process is not sufficient to recover the initial EPR signal. The peaks of the corresponding diffraction pattern also show a significant intensity reduction. This stage can be therefore taken as the beginning of the HKUST-1 hydrolysis. ${ }^{[35]}$ These results are supported also by many other works that have found a lowering of the coordination of the copper units, leading exactly to the formation of $\mathrm{Cu}^{2+} / \mathrm{Cu}^{+}$unities, affecting the catalytic performances and the chemical reactivity. ${ }^{[59]}$

Xue and co-authors ${ }^{[55]}$ have found that at least three water molecules per paddlewheel in its local environment occur to totally detach one ligand. ${ }^{[55]}$ However, their model of "decomposed paddlewheel" obtained via DFT calculation was slightly different from that reported by Todaro and co-authors: indeed in their structure the $\mathrm{Cu}-\mathrm{O}$ bond involving the second $\mathrm{Cu}^{2+}$ has been broken by ligand displacement and, even though the whole ligand has been consequently detached, each copper ion maintains the same number of bonds, because the water oxygens take the place of the carboxylate oxygens (Figure 6).

Third stage: the relaxation into a more stable configuration. From the $50^{\text {th }}$ to the $180^{\text {th }}$ day, Todaro and co-authors ${ }^{[35]}$ observed a further progressive narrowing of the resonance detectable at $300 \mathrm{~K}$ and also the presence of a characteristic hyperfine quadruplet on the main peak visible at $77 \mathrm{~K}$ and arising from the $\mathrm{Cu}^{2+} / \mathrm{Cu}^{+}$paddlewheels (Figures 3 and 4). This would be the effects of the last stage of the decomposition process. Todaro and co-authors have described how the 
relaxation leads to a new $S=1 / 2$ spin center named $E^{\prime} 2(\mathrm{Cu})$ (Figure 7e), arisen after the further detaching of a second carboxylate bridge from the $\mathrm{Cu}^{2+} / \mathrm{Cu}^{+}$paddlewheel of the $\mathrm{E}^{\prime} 1(\mathrm{Cu})$ center. ${ }^{[35]}$ The new structure has then two detached carboxylate bridges facing one another, so that the $\mathrm{Cu}^{+}$has a T-shaped configuration and the $\mathrm{Cu}^{2+}$ ion, coordinated to a water molecule, maintains the square-pyramidal geometry. ${ }^{[35]}$ The characteristic hyperfine quadruplet, again easily resolvable in this last stage, would indicate the loss of the strain found in the $E^{\prime} 1(\mathrm{Cu})$ center. ${ }^{[35]}$

Forth stage: the conversion to monomeric complexes. Todaro and co-authors suggested that the $E^{\prime} 2(\mathrm{Cu})$ center is stable enough to be considered the final stage of the decomposition process. ${ }^{[35]}$ In contrast, Pöppl and co-authors ${ }^{[43]}$ have also studied the degradation process occurred in HKUST-1 upon exposure to air moisture, and they individuated a strong similarity between the spectroscopic parameters of the final product of the decomposed HKUST-1 and those of the $\left[\mathrm{Cu}\left(\mathrm{H}_{2} \mathrm{O}\right)_{6}\right]^{2+}$ monomeric complexes. ${ }^{[43,44]}$ For this reason, they suggest that in the final products of the decomposition process of HKUST-1 exposed to air there are coppers completely cut off from the framework and possibly arranged in mononuclear complexes. ${ }^{[43]}$ Similar results involving the presence of a subsequent stage involving only paramagnetic monomeric $\mathrm{Cu}^{2+}$ centers have also been suggested by Terracina and co-authors. ${ }^{[60]}$

The hydrated HKUST-1 samples have been investigated also by SEM images (Figure 8) acquired after different exposure time by Todaro and co-authors. ${ }^{[35]}$ Even though no morphological change is observed after the first 20 days (that is, when only E' $(\mathrm{Cu})$ silent center and $\mathrm{E}^{\prime \prime}(\mathrm{Cu})$ centers co-exist in the material) compared to the pristine material, after 36 and 188 days of hydration, small holes appear on the surface of the grains. Thus, these results are in perfect agreement with the EPR results above mentioned. ${ }^{[35]}$
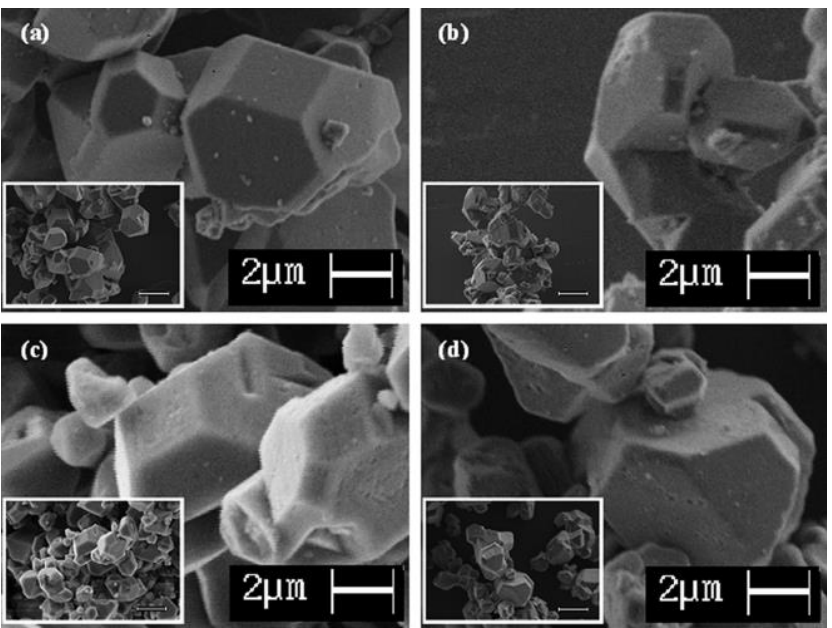

Figure 8 SEM images of a sample of HKUST-1 exposed to air $(300 \mathrm{~K}, 70 \% \mathrm{RH})$ for different times: (a) pristine material $(0$ days of hydration), (b) 20 , (c) 36 , and (d) 188 days. Reprinted with permission from J. Phys. Chem. C 2016, 120, 12879-12889. Copyright 2016 American Chemical Society. ${ }^{[35]}$

\section{Other considerations}

In the last years, several efforts have been spent on the research of methods to preserve HKUST-1 (or more in general water sensitive MOFs) from destructive interaction with water. ${ }^{[38,61,64,65]}$ For example, in some works many researchers have tried to introduce hydrophobic component which would fill the pores limiting the possibility of water condensation or to build a kind of surface barrier, like an external hydrophobic layer. ${ }^{[38,61,64,65]}$ Unfortunately, these methods typically require a not negligible price in terms of pore accessibility. ${ }^{[38,64]}$ Other studies have focused on the fact that hydrolysis induces superficial defects already creating a sort of surface barrier, which prevents the interaction of the internal pores with potential external gases or substances. In principle, healing such surface barrier might recover the properties of the pristine MOF. ${ }^{[66-70]}$ For example, Müller and co-authors ${ }^{[66]}$ found an easy method to dissolve such surface defects and then recover the pristine performances; however, such dissolving process led to a loss of about $20 \%$ in mass of the material. Finally, McHugh and co-authors ${ }^{[21]}$ suggested that hydrolytic stability can be induced in a MOF like HKUST-1 introducing sacrificial bonds between the $\mathrm{Cu}$ centers and the carboxylate ligands. Such idea led to the design of the MOF STAM-17-OEt, which we will discuss in the section of "Comparison with Other Copper Carboxylate MOFs: STAM-1 and STAM-17-OEt".

\section{Role of humidity on mechanical compaction processes}

Recently, Terracina and co-authors ${ }^{[56]}$ deeply characterized the role and the effects of the water molecules during the phases of the production of HKUST-1 tablets. This detailed study has been made possible by the development of a new method involving EPR spectroscopy, which allows the estimation of the amount of damages induced in the MOF structure upon the application of a mechanical pressure. In other words, they have been able to recognize for the first time that, as occurs upon hydrolysis, the tableting process always induces the formation of $S=1 / 2$ paramagnetic centers in the materials, arising from the distortion and/or breaking of a variable fraction of the paddlewheels of the material. The authors have observed that the number of damaged paddlewheels increases on increasing the applied pressure. From this method, one can obtain quantitative estimates how many paddlewheels have been affected by mechanical compaction in correspondence of the metal group (Figure 9). ${ }^{[56]}$

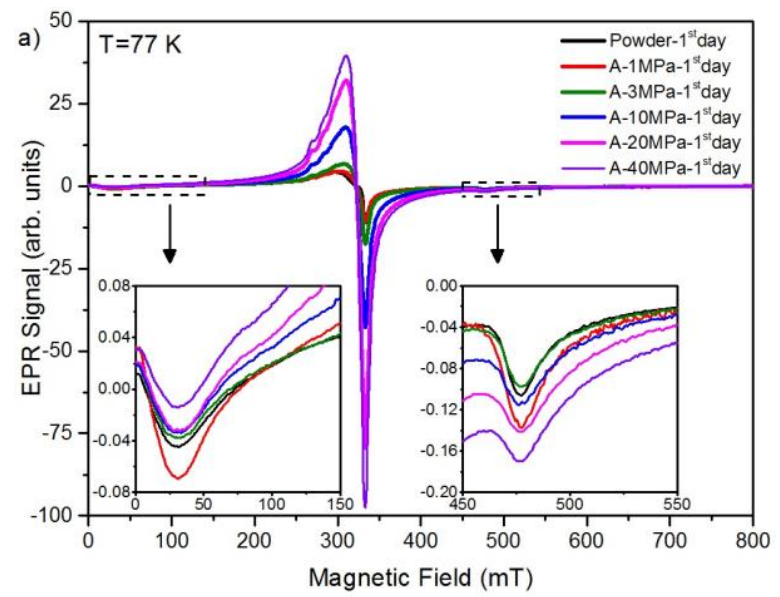

Figure 9 EPR spectra of some representative tablets obtained just after tableting and of the powder sample (in black), acquired at $77 \mathrm{~K}$. The pressure applied ranges from 0 (powder sample) to $40 \mathrm{MPa}$. The insets in both the graphs (a) and (b) show the zooms of the spectrum regions enclosed by the dashed panels. Reprinted with permission from J. Phys. Chem. C 2018, 123, 1730-1741. Copyright 2018 American Chemical Society. ${ }^{[56]}$ 
Furthermore, by applying this method to the tablets produced from powder differently hydrated, they have unveiled that the number of defects (individuated as $S=1 / 2$ spin centers emerged upon the packaging treatments) is strictly related to the level of hydration of the starting powders. In the tablets produced starting from HKUST-1 activated powders, a negligible of degradation has been observed: the percentage of paddlewheels damaged by tableting with a pressure of about 40 $\mathrm{MPa}$ has been estimated to be as low as $4 \%$. But there is more: the authors have found that an additional thermal activation just after the compaction can further reduce this defective EPR component, to the point that the properties of these tablets become virtually indistinguishable from those of pristine activated powders (even for the tablets produced by applying 40 $\mathrm{MPa}$ of pressure), except, obviously, for the bulk density.

The BET surface areas of the tablets have confirmed that the tablets produced have an optimal inner porosity, comparable to that of the starting powder (Table 1). On the contrary, using powder samples with different degrees of hydration, the EPR spectra acquired after their compaction have highlighted a strong presence of defects, which increase on increasing the hydration. ${ }^{[56]}$

Table 1 BET surface area of the HKUST-1 powder sample compared with that of some of the tablets produced from activated powders

\begin{tabular}{|c|c|}
\hline Sample & BET area ${ }^{a} /\left(\mathrm{m}^{2} / \mathrm{g}\right)$ \\
\hline Powder & 1620 \\
\hline $40 \mathrm{MPa}$ & 1685 \\
\hline $40 \mathrm{MPa}$ reactivated ${ }^{b}$ & 1935 \\
\hline $40 \mathrm{MPa}$, after 5 weeks & 1848 \\
\hline $40 \mathrm{MPa}$ reactivated, ${ }^{b}$ after 5 weeks & 1622 \\
\hline
\end{tabular}

${ }^{a}$ The analysis has been performed in the relative pressure range of the increasing trend of the Rouquerol plot. ${ }^{b}$ Reactivated just after the compaction.

Furthermore, prolonging the EPR study up to five weeks from the compaction (of activated, slightly hydrated or highly hydrated powders), it has been found that the tablets produced by activated powders and reactivated just after the mechanical tableting were the only which did not show any sign of delayed structural instability, even after five weeks. ${ }^{[56]}$

Summarizing, following this specific albeit simple compaction protocol, the authors proved that it is possible to obtain a stable HKUST-1 tablet having a structure with the pristine porosity and crystallinity but with a high bulk density, simply taking care to activate the material just before and just after tableting.

\section{Comparison with Other Copper Carboxylate MOFS: STAM-1 and STAM-17- OEt}

In order to better understand the causes of the trigger of hydrolysis in HKUST-1 (but also, more in general, in MOFs), it can be useful to involve in the study also other similar structure. In the following, we will talk about two other copper carboxylate MOFs, which are water stable despite the similarities with HKUST-1 material. Although these two MOFs have the same copper paddle-wheel building units of HKUST-1 (Figure 10a), instead of the BTC linker (Figure 10b), the organic linkers which compose STAM-1 and STAM-17-OEt are monomethyl BTC linker (Figure 10c) and 5-ethoxy isophthalate linker (Figure 10d), respectively.

The resulting frameworks have different topologies and properties. ${ }^{[20,21]}$ More in detail, both STAM-1 and STAM-17-OEt exhibit flexibility triggered by adsorption/removal of water and, furthermore, STAM-17-OEt also shows the presence of a)

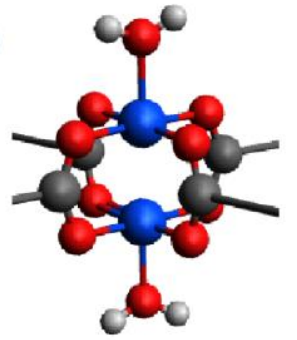

c)

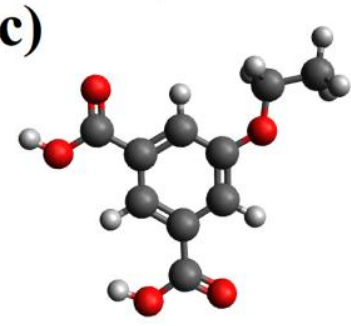

b)

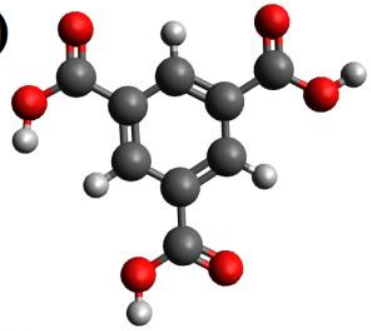

d)

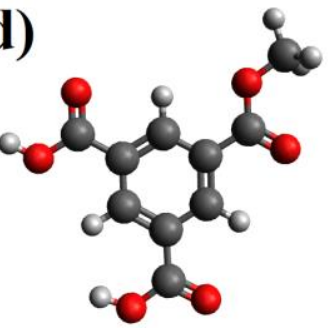

Figure 10 Components of the MOFs HKUST-1, STAM-1, and STAM-17-OEt: (a) copper paddle-wheel unit, (b) BTC linker (for HKUST-1), (c) monomethyl BTC linker (for STAM-1), and (d) 5-ethoxy isophthalate linker (for STAM-17-OEt). Reprinted and adapted with permission from J. Phys. Chem. C 2019, 123, 28219-28232. Copyright 2019 American Chemical Society. ${ }^{[60]}$

"crumple zones", or else weak interactions between near dehydrated paddlewheels that can be broken upon interaction with water. The presence of such "sacrificial bonds" makes it "hemilabile". Unfortunately, compared to HKUST-1, they have a significantly lower inner porosity and surface area. ${ }^{[20,21]}$

The reasons why both STAM-1 and STAM-17-OEt, in contrast to HKUST-1, are water stable are still object of study. However, Terracina and co-authors ${ }^{[60]}$ carried out a comparative atomic-scale study focused on the different water stability of HKUST-1, STAM-1 and STAM-17-OEt MOFs, obtaining remarkable results. Under the exposure conditions they have used, HKUST-1 has begun the process of irreversible decomposition within $24 \mathrm{~h}$ whereas, in contrast, STAM-17-OEt has shown no evidence of hydrolysis effects during the entire period of $60 \mathrm{~d}$ of monitoring. A similar conclusion has been reached for STAM-1. Consequently, both STAM-1 and STAM-17-OEt have been found strongly resistant to water, even at atomic scale level, and they had not decomposed under the conditions used, attesting the far longer resistance towards water of STAM-1 and STAM-17-OEt materials compared to HKUST-1. ${ }^{[60]}$ However, surprisingly enough, the first hours of exposure to water have led to an unexpected virtually indistinguishable evolution in all of the MOFs involved: in fact, during the first six hours of hydration, the samples have exhibited comparable spectroscopic changes, connectible with the adsorption of the first water molecule on the axial sites of the $\mathrm{Cu}^{2+}$ ions. ${ }^{[60]}$ This result is very meaningful, because it confirms that the hydrolytic stability of this type of MOFs take over not during the first adsorption on site I (Figure 1) but at a later stage, during the adsorption of additional water molecules on the firsts (site l'), as many theories have claimed (see previous sections of this review). The authors, accordingly with previous literature, have suggested that when on average more than one water molecule approaches each copper ion of the paddle-wheel, the differences in evolution rise up. ${ }^{[60]}$

These considerations can provide an answer to the question: why three similar MOFs have such a different water stability? In fact, such difference may be reasonably linked to the amount of free space available in the pores of the materials: indeed, the pore size is significantly larger in HKUST-1 than in 
STAM-1 and STAM-17-OEt. It must be said also that other theories have been suggested, for example, involving that a significant role is determined by the hemilability property of the MOF STAM-17-OEt. In this view, HKUST-1 would undergo hydrolysis immediately after the adsorption of the first water molecules, whereas in STAM-17-OEt this $\mathrm{Cu}-\mathrm{O}$ breakage would be prevented because of the breakage of the sacrificial bonds or "crumple zones", which require a minor energy quantity. ${ }^{[21]}$ However, this is in sharp contrast with the common evolution between HKUST-1 and STAM-17-OEt observed during the first few hours and, furthermore, with the reversibility of such earlier phases.

\section{Conclusions and Perspectives}

Since the beginning of the research on MOFs, their susceptibility to hydrolysis has been highlighted and a huge number of works have been published in not more than two decades.

A certain quantity of highly stable MOF structures have been developed, but they are only a tiny percentage compared to the totality of MOFs. Furthermore, despite being relatively easy to obtain a higher confidence about the instability of a MOF, the opposite is not simple. For this reason, more systematic experimental studies are still necessary in order to deeply characterize the water stability properties of lots of MOFs and, even more, the causes of their behavior, involving as many techniques as possible.

After a long and focused work carried out on HKUST-1, a deep understanding about the degradation mechanism induced by hydrolysis has been reached, with a complete comprehension about the stability limits of the material, as well as the development of a simple protocol which allows the production of compacted HKUST-1 powders, as displayed also in this review. Even some strategies to prevent hydrolysis in HKUST-1 have been developed, although they cannot fully solve the issue, because the performances of such materials result likewise compromised. Similarly, the development of copper carboxylate MOFs which are highly water stable seems also promising even though not yet complete, since the performances of such resistant MOFs known until today are not equally promising as those of HKUST-1.

\section{Acknowledgement}

The authors would like to thank people of the LAMP group (http://www.unipa.it/lamp/) at the Department of Physics and Chemistry of University of Palermo for useful discussions and comments.

\section{Author Contributions}

Both the authors collected relevant literatures, wrote, revised and organized this manuscript.

\section{Conflict of Interest}

The authors declare no conflict of interest.

Copyright (c) 2021 Angela Terracina and Gianpiero Buscarino. This article is an open access article distributed under the terms and conditions of the Creative Commons Attribution (CC BY) license (http://creativecommons.org/licenses/by/4.0/). The use, distribution or reproduction in other forums is permitted, provided the original author(s) or licensor are credited and that the original publication in this journal is cited, in accordance with accepted academic practice. No use, distribution or reproduction is permitted which does not comply with these terms.

\section{References}

[1] Yaghi, O. M.; Kalmutzki, M. J.; Diercks, C. S. In Introduction to Reticular Chemistry: Metal-Organic Frameworks and Covalent Organic Frameworks. John Wiley \& Sons, 2019.

[2] Furukawa, H.; Cordova, K. E.; O'Keeffe, M.; Yaghi, O. M. The chemistry and applications of metal-organic frameworks. Science 2013, 341, 1230444

[3] Rowsell, J. L.; Yaghi, O. M. Metal-organic frameworks: a new class of porous materials. Micr. Mes. Mat. 2004, 73, 3-14.

[4] Tan, K.; Nijem, N.; Gao, Y.; Zuluaga, S.; Li, J.; Thonhauser, T.; Chabal, Y. J. Water interactions in metal organic frameworks. CrystEngComm 2015, 17, 247-260.

[5] Moghadam, P. Z.; Li, A.; Wiggin, S. B.; Tao, A.; Maloney, A.G., Wood, P.A.; Ward, S.C. and Fairen-Jimenez, D. Development of a Cambridge Structural Database subset: a collection of metal-organic frameworks for past, present, and future. Chem. Mater. 2017, 29, 2618-2625.

[6] Eddaoudi, M.; Kim, J.; Rosi, N.; Vodak, D.; Wachter, J.; O'Keeffe, M.; Yaghi, O. M. Systematic design of pore size and functionality in isoreticular MOFs and their application in methane storage. Science 2002, 295, 469-472.

[7] Kuppler, R. J.; Timmons, D. J.; Fang, Q. R.; Li, J. R.; Makal, T. A.; Young, M. D.; Yuan, D.; Zhao, D.; Zhuang, W.; Zhou, H. C. Potential applications of metal-organic frameworks. Coord. Chem. Rev. 2009, 253, 3042-3066.

[8] Burtch, N. C.; Jasuja, H.; Walton, K. S. Water stability and adsorption in metal-organic frameworks. Chem. Rev. 2014, 114, 10575-10612.

[9] Khan, N. A.; Hasan, Z.; Jhung, S. H. Adsorptive removal of hazardous materials using metal-organic frameworks (MOFs): a review. J. Hazard Mater. 2013, 244, 444-456.

[10] McKinlay, A. C.; Morris, R. E.; Horcajada, P.; Férey, G.; Gref, R.; Couvreur, P.; Serre, C. Protecting group and switchable pore-discriminating adsorption properties of a hydrophilic-hydrophobic metal-organic framework. Angew. Chem. Int. Ed. 2010, 49, 6260-6266.

[11] Li, S. L.; Xu, Q. Metal-organic frameworks as platforms for clean energy. Energ. Environ. Sci. 2013, 6, 1656-1683.

[12] Liu, J.; Thallapally, P. K.; McGrail, B. P.; Brown, D. R.; Liu, J. Progress in adsorption-based $\mathrm{CO}_{2}$ capture by metal-organic frameworks. Chem. Soc. Rev. 2012, 41, 2308-2322.

[13] Editorial Staff. Frameworks for Commercial Success. Nat. Chem. 2016, 8, p. 987.

[14] Kim, H.; Yang, S.; Narayanan, S.; Umans, A. S.; Wang, E. N.; Rao, S. R. Sorption-based Atmospheric Water Harvesting Device. US 10,640,954, 2020

[15] Canivet, J.; Fateeva, A.; Guo, Y.; Coasne, B.; Farrusseng, D. Water adsorption in MOFs: fundamentals and applications. Chem. Soc. Rev. 2014, 43, 5594-5617.

[16] Nandasiri, M. I.; Jambovane, S. R.; McGrail, B. P.; Schaef, H. T.; Nune, S. K. Adsorption, separation, and catalytic properties of densified metal-organic frameworks. Coord. Chem. Rev. 2016, 311, 38-52.

[17] Ren, J.; Langmi, H. W.; North, B. C.; Mathe, M. Review on processing of metal-organic framework (MOF) materials towards system integration for hydrogen storage. Int. J. Energ. Res. 2015, $39,607-620$.

[18] Chui, S. S. Y.; Lo, S. M. F.; Charmant, J. P.; Orpen, A. G.; Williams, I. D. A chemically functionalizable nanoporous material $\left[\mathrm{Cu}_{3}(\mathrm{TMA})_{2}\left(\mathrm{H}_{2} \mathrm{O}\right)_{3}\right]_{n}$. Science 1999, 283, 1148-1150.

[19] Hendon, C. H.; Walsh, A. Chemical principles underpinning the performance of the metal-organic framework HKUST-1. Chem. Sci. 2015, 6, 3674-3683.

[20] Mohideen, M. I. H.; Xiao, B.; Wheatley, P. S.; McKinlay, A. C.; Li, Y.; Slawin, A. M.; Aldous, D. W.; Cessford, N. F.; Düren, T.; Zhao, X.; Gill, R. Protecting group and switchable pore-discriminating 
adsorption properties of a hydrophilic-hydrophobic metal-organic framework. Nat. Chem. 2011, 3, 304-310.

[21] McHugh, L. N.; McPherson, M. J.; McCormick, L. J.; Morris, S. A.; Wheatley, P. S.; Teat, S. J.; McKay, D.; Dawson, D. M.; Sansome, C. E.; Ashbrook, S. E.; Stone, C. A. Hydrolytic stability in hemilabile metal-organic frameworks. Nat. Chem. 2018, 10, 1096-1102.

[22] Dawson, D. M.; Jamieson, L. E.; Mohideen, M. I. H.; McKinlay, A. C.; Smellie, I. A.; Cadou, R.; Keddie, N. S.; Morris, R. E. and Ashbrook, S. E. High-resolution solid-state 13C NMR spectroscopy of the paramagnetic metal-organic frameworks, STAM-1 and HKUST-1. Phys. Chem. Chem. Phys. 2013, 15, 919-929.

[23] Dawson, D. M.; Sansome, C. E.; McHugh, L. N.; McPherson, M. J.; McPherson, L. J. M.; Morris, R. E.; Ashbrook, S. E. ${ }^{13} \mathrm{C}$ NMR of "crumple zone" $\mathrm{Cu}(\mathrm{II})$ isophthalate metal-organic frameworks. Solid State Nucl. Mag. 2019, 101, 44-50.

[24] Makal, T. A.; Li, J. R.; Lu, W.; Zhou, H. C. Methane storage in advanced porous materials. Chem. Soc. Rev. 2012, 41, 7761-7779.

[25] Yang, S.; Sun, J.; Ramirez-Cuesta, A. J.; Callear, S. K.; David, W. I.; Anderson, D. P.; Newby, R.; Blake, A. J.; Parker, J. E.; Tang, C. C.; Schröder, M. Selectivity and direct visualization of carbon dioxide and sulfur dioxide in a decorated porous host. Nat. Chem. 2012, 4, 887-894.

[26] Taylor, J. M.; Dawson, K. W.; Shimizu, G. K. A water-stable metal-organic framework with highly acidic pores for proton-conducting applications. J. Am. Chem. Soc. 2013, 135, 1193-1196.

[27] Low, J. J.; Benin, A. I.; Jakubczak, P.; Abrahamian, J. F.; Faheem, S. A.; Willis, R. R. Virtual high throughput screening confirmed experimentally: porous coordination polymer hydration. J. Am. Chem. Soc. 2009, 131, 15834-15842.

[28] Bellarosa, L.; Castillo, J. M.; Vlugt, T.; Calero, S.; López, N. On the mechanism behind the instability of isoreticular metal-organic frameworks (irmofs) in humid environments. Chem.-Eur. J. 2012, $18,12260-12266$

[29] De Toni, M.; Jonchiere, R.; Pullumbi, P.; Coudert, F. X.; Fuchs, A. H. How Can a Hydrophobic MOF be Water-Unstable? Insight into the Hydration Mechanism of IRMOFs. ChemPhysChem 2012, 13, 3497-3503.

[30] Worrall, S. D.; Bissett, M. A.; Hill, P. I.; Rooney, A. P.; Haigh, S. J.; Attfield, M. P.; Dryfe, R. A. Metal-organic framework templated electrodeposition of functional gold nanostructures. Electrochim. Acta 2016, 222, 361-369.

[31] Prestipino, C.; Regli, L.; Vitillo, J. G.; Bonino, F.; Damin, A.; Lamberti, C.; Zecchina, A.; Solari, P. L.; Kongshaug, K. O.; Bordiga, S. Local structure of framework $\mathrm{Cu}(\mathrm{II})$ in HKUST-1 metallorganic framework: spectroscopic characterization upon activation and interaction with adsorbates. Chem. Mat. 2006, 18, 1337-1346.

[32] Chowdhury, P.; Bikkina, C.; Meister, D.; Dreisbach, F.; Gumma, S. Comparison of adsorption isotherms on Cu-BTC metal organic frameworks synthesized from different routes. Micropor. Mesopor. Mat. 2009, 117, 406-413.

[33] Tian, T.; Zeng, Z.; Vulpe, D.; Casco, M. E.; Divitini, G.; Midgley, P. A.; Silvestre-Albero, J.; Tan, J. C.; Moghadam, P. Z. and Fairen-Jimenez, D. A sol-gel monolithic metal-organic framework with enhanced methane uptake. Nat. Mat. 2018, 17, 174-179.

[34] Peng, Y.; Krungleviciute, V.; Eryazici, I.; Hupp, J. T.; Farha, O. K.; Yildirim, T. Methane storage in metal-organic frameworks: current records, surprise findings, and challenges. J. Am. Chem. Soc. 2013, 135, 11887-11894.

[35] Todaro, M.; Buscarino, G.; Sciortino, L.; Alessi, A.; Messina, F.; Taddei, M.; Ranocchiari, M.; Cannas, M.; Gelardi, F. M. Decomposition process of carboxylate MOF HKUST-1 unveiled at the atomic scale level. J. Phys. Chem. C 2016, 120, 12879-12889.

[36] Todaro, M.; Alessi, A.; Sciortino, L.; Agnello, S.; Cannas, M.; Gelardi, F. M.; Buscarino, G. Investigation by Raman spectroscopy of the decomposition process of HKUST-1 upon exposure to air. $J$. Spectrosc. 2016.

[37] Todaro, M.; Sciortino, L.; Gelardi, F. M. and Buscarino, G. Deter- mination of Geometry Arrangement of Copper lons in HKUST-1 by XAFS during a Prolonged Exposure to Air. J. Phys. Chem. C 2017, 121, 24853-24860.

[38] Decoste, J. B.; Peterson, G. W.; Smith, M. W.; Stone, C. A.; Willis, C. R. Enhanced stability of Cu-BTC MOF via perfluorohexane plasma-enhanced chemical vapor deposition. J. Am. Chem. Soc. 2012, 134, 1486-1489.

[39] Küsgens, P.; Rose, M.; Senkovska, I.; Fröde, H.; Henschel, A.; Siegle, S.; Kaskel, S. Characterization of metal-organic frameworks by water adsorption. Micropor. Mesopor. Mat. 2009, 120, 325-330.

[40] Schoenecker, P. M.; Carson, C. G.; Jasuja, H.; Flemming, C. J.; Walton, K. S. Effect of water adsorption on retention of structure and surface area of metal-organic frameworks. Ind. Eng. Chem. Res. 2012, 51, 6513-6519.

[41] DeCoste, J. B.; Peterson, G. W.; Schindler, B. J.; Killops, K. L.; Browe, M. A.; Mahle, J. J. The effect of water adsorption on the structure of the carboxylate containing metal-organic frameworks Cu-BTC, Mg-MOF-74, and UiO-66. J. Mat. Chem. A 2013, 1, 11922-11932.

[42] Tan, K.; Nijem, N.; Canepa, P.; Gong, Q.; Li, J.; Thonhauser, T.; Chabal, Y. J. Stability and hydrolyzation of metal organic frameworks with paddle-wheel SBUs upon hydration. Chem. Mat. 2012, 24, 3153-3167.

[43] Pöppl, A.; Jee, B.; Icker, M.; Hartmann, M.; Himsl, D. Untersuchungen zur chemischen Stabilität von $\mathrm{Cu}_{3}(\mathrm{btc})_{2}$ (HKUST-1) durch $\mathrm{N}_{2}$-Adsorption, Röntgenpulverdiffraktometrie und EPR-Spektroskopie. Chem-Ing-Tech 2010, 82, 1025-1029.

[44] Jee, B. CW and Pulsed EPR Spectroscopy of CU (II) and V (IV) in Metal-Organic Framework Compounds: Metal Ion Coordination and Adsorbate Interactions, Ph.D. Dissertation, Universität Leipzig, Leipzig, Germany, 2013.

[45] Mazaj, M.; Čendak, T.; Buscarino, G.; Todaro, M.; Logar, N.Z. Confined crystallization of a HKUST-1 metal-organic framework within mesostructured silica with enhanced structural resistance towards water. J. Mat. Chem. A 2017, 5, 22305-22315.

[46] Gul-E-Noor, F.; Michel, D.; Krautscheid, H.; Haase, J.; Bertmer, M. Time dependent water uptake in $\mathrm{Cu}_{3}(\mathrm{btc})_{2}$ MOF: Identification of different water adsorption states by ${ }^{1} \mathrm{H}$ MAS NMR. Micropor Mesopor. Mat. 2013, 180, 8-13.

[47] Castillo, J. M.; Vlugt, T. J.; Calero, S. Understanding water adsorption in Cu-BTC metal-organic frameworks. J. Phys. Chem. C 2008, 112, 15934-15939.

[48] Panella, B.; Hirscher, M.; Pütter, H.; Müller, U. Hydrogen adsorption in metal-organic frameworks: Cu-MOFs and Zn-MOFs compared. Adv. Funct. Mater. 2006, 16, 520-524.

[49] Wang, Q. M.; Shen, D.; Bülow, M.; Lau, M. L.; Deng, S.; Fitch, F. R.; Lemcoff, N. O.; Semanscin, J. Metallo-organic molecular sieve for gas separation and purification. Micropor. Mesopor. Mater. 2002, 55, 217-230.

[50] Schlichte, K.; Kratzke, T.; Kaskel, S. Improved synthesis, thermal stability and catalytic properties of the metal-organic framework compound $\mathrm{Cu}_{3}(\mathrm{BTC})_{2}$. Micropor. Mesopor. Mater. 2004, 73, 81-88.

[51] Al-Janabi, N.; Hill, P.; Torrente-Murciano, L.; Garforth, A.; Gorgojo, P.; Siperstein, F.; Fan, X. Mapping the Cu-BTC metal-organic framework HKUST-1 stability envelope in the presence of water vapour for $\mathrm{CO}_{2}$ adsorption from flue gases Chem. Eng. J. 2015, 281, 669-677.

[52] Kim, H. K.; Yun, W. S.; Kim, M. B.; Kim, J. Y.; Bae, Y. S.; Lee, J.; Jeong, N. C. A chemical route to activation of open metal sites in the copper-based metal-organic framework materials HKUST-1 and Cu-MOF-2. J. Am. Chem. Soc. 2015, 137, 10009-10015.

[53] Grajciar, L.; Bludsky, O.; Nachtigall, P. Water adsorption on coordinatively unsaturated sites in CuBTC MOF. J. Phys. Chem. Lett. 2010, 1, 3354-3359

[54] Toda, J.; Fischer, M.; Jorge, M.; Gomes, J. R. Water adsorption on 
a copper formate paddlewheel model of CuBTC: A comparative MP2 and DFT study. Chem. Phys. Lett. 2013, 587, 7-13.

[55] Xue, W.; Zhang, Z.; Huang, H.; Zhong, C.; Mei, D. Theoretical Insight into the Initial Hydrolytic Breakdown of HKUST-1. J. Phys. Chem. C 2019, 124, 1991-2001.

[56] Terracina, A.; Todaro, M.; Mazaj, M.; Agnello, S.; Gelardi, F. M. and Buscarino, G. Unveiled the Source of the Structural Instability of HKUST-1 Powders upon Mechanical Compaction: Definition of a Fully Preserving Tableting Method. J. Phys. Chem. C 2018, 123, 1730-1741.

[57] Giovine, R.; Pourpoint, F.; Duval, S.; Lafon, O.; Amoureux, J. P.; Loiseau, T.; Volkringer, C. The Surprising Stability of $\mathrm{Cu}_{3}(\mathrm{btc})_{2}$ Metal-Organic Framework under Steam Flow at High Temperature. Cryst. Growth Des. 2018, 18, 6681-6693.

[58] Gul-E-Noor, F.; Jee, B.; Pöppl, A.; Hartmann, M.; Himsl, D.; Bertmer, M. Effects of varying water adsorption on a $\mathrm{Cu}_{3}(\mathrm{BTC})_{2}$ metal-organic framework (MOF) as studied by ${ }^{1} \mathrm{H}$ and ${ }^{13} \mathrm{C}$ solid-state NMR spectroscopy. Phys. Chem. Chem. Phys. 2011, 13, 7783-7788.

[59] St. Petkov, P.; Vayssilov, G. N.; Liu, J.; Shekhah, O.; Wang, Y.; Wöll, C.; Heine, T. Defects in MOFs: a thorough characterization. ChemPhysChem 2012, 13, 2025-2029.

[60] Terracina, A.; McHugh, L. N.; Todaro, M.; Agnello, S.; Wheatley, P. S.; Gelardi, F. M.; Morris, R. E.; Buscarino, G. Multitechnique Analysis of the Hydration in Three Different Copper Paddle-Wheel Metal-Organic Frameworks. J. Phys. Chem. C 2019, 123, 28219-28232.

[61] Wang, T.; Zhu, H.; Zeng, Q. and Liu, D. Strategies for Overcoming Defects of HKUST-1 and Its Relevant Applications. Adv. Mater. Interfaces 2019, 6, 1900423.

[62] Safy, M. E.; Amin, M.; Haikal, R. R.; Elshazly, B.; Wang, J.; Wang, Y.; Wöll, C.; Alkordi, M. H. Probing the Water Stability Limits and Degradation Pathways of Metal-Organic Frameworks (MOFs). Chem.-Eur. J. 2020

[63] Pöppl, A.; Kunz, S.; Himsl, D.; Hartmann, M. CW and Pulsed ESR Spectroscopy of Cupric lons in the Metal-Organic Framework
Compound $\mathrm{Cu}_{3}(\mathrm{BTC})_{2}$. J. Phys. Chem. C 2008, 112, 2678-2684.

[64] Carné-Sánchez, A.; Stylianou, K. C.; Carbonell, C.; Naderi, M.; Imaz, I. and Maspoch, D. Protecting Metal-Organic Framework Crystals from Hydrolytic Degradation by Spray-Dry Encapsulating Them into Polystyrene Microspheres. Adv. Mater. 2015, 27, 869-873.

[65] Lin, Z.; Lv, Z.; Zhou, X.; Xiao, H.; Wu, J.; Li, Z. Postsynthetic strategy to prepare ACN@Cu-BTCs with enhanced water vapor stability and $\mathrm{CO}_{2} / \mathrm{CH}_{4}$ separation selectivity. Ind. Eng. Chem. Res. 2018, 57, 3765-3772.

[66] Müller, K.; Vankova, N.; Schöttner, L.; Heine, T. and Heinke, L. Dissolving uptake-hindering surface defects in metal-organic frameworks. Chem. Sci. 2019, 10, 153-160.

[67] Majano, G.; Martin, O.; Hammes, M.; Smeets, S.; Baerlocher, C. and Pérez-Ramírez, J. Solvent-Mediated Reconstruction of the Metal-Organic Framework HKUST-1 $\left(\mathrm{Cu}_{3}(\mathrm{BTC})_{2}\right)$. Adv. Funct. Mater. 2014, 24, 3855-3865.

[68] Sun, X.; Li, H.; Li, Y.; Xu, F.; Xiao, J.; Xia, Q.; Li, Y.; Li, Z. A novel mechanochemical method for reconstructing the moisture-degraded HKUST-1. Chem. Commun. 2015, 51, 10835-10838.

[69] Das, S. K.; Chatterjee, S.; Bhunia, S.; Mondal, A.; Mitra, P.; Kumari, V.; Pradhan, A. and Bhaumik, A. A new strongly paramagnetic cerium-containing microporous MOF for $\mathrm{CO}_{2}$ fixation under ambient conditions. Dalton Trans. 2017, 46, 13783-13792.

[70] Gumilar, G.; Kaneti, Y. V.; Henzie, J.; Chatterjee, S.; Na, J.; Yuliarto, B.; Nugraha, N.; Patah, A.; Bhaumik, A. and Yamauchi, Y. General synthesis of hierarchical sheet/plate-like M-BDC $(\mathrm{M}=\mathrm{Cu}$, $\mathrm{Mn}, \mathrm{Ni}$, and $\mathrm{Zr}$ ) metal-organic frameworks for electrochemical non-enzymatic glucose sensing. Chem. Sci. 2020 11, 3644-3655.

Received April 1, 2021 Accepted May 13, 2021 